\title{
The end of the Holocene Humid Period in the central Sahara and Thar deserts: societal collapses or new opportunities?
}

\author{
Andrea Zerboni', S. Biagetti ${ }^{2,3,4}$, C. Lancelotti ${ }^{2,3}$ and M. Madella ${ }^{2,3,5}$
}

\section{The end of the Holocene Humid Period heavily impacted on human societies, prompting the development of new forms of social complexity and strategies for food security. Yearly climatic oscillations played a role in enhancing the resilience of past societies.}

The Holocene Humid Period or Holocene Climatic Optimum (ca. 12-5 ka BP), in its local, monsoon-tuned variants of the African Humid Period (DeMenocal et al. 2000; Gasse 2000) and the period of strong Asian southwest (or summer) monsoon (Dixit et al. 2014), is one of the best-studied climatic phases of the Holocene. Yet the ensuing trend towards aridity, the surface processes shaping the present-day arid lands and the cultural responses to these are still debated. Human reactions to arid environmental conditions have been sometimes described in terms of demographic decrease (e.g. Manning and Timpson 2014) and as driving socio-cultural complexity (e.g. Kuper and Kröpelin 2006). These two concepts, although apparently conflicting, are not mutually exclusive. The onset of arid conditions can lead to demographic decrease or the rearrangement of the population around important or secure resources. In turn, this can favor the adoption of different strategies to cope with the new climatic conditions, leading to augmented social stratification and complexity, and eventually to the emergence of hierarchical state-like entities.

\section{The transition toward aridity}

The African Humid Period is regarded as the most favorable period for human settlement in northern Africa during the Holocene. It corresponds to the so-called Green Sahara, often seen as the apex of Saharan prehistoric civilizations. Its termination represents a crucial moment for past communities. Whether the African Humid Period ended abruptly (e.g. deMenocal et al. 2000) or gradually (Kröpelin et al. 2008) is still discussed. In the SW Fazzan of Libya (Fig. 1), its end (around $5.5 \mathrm{ka} \mathrm{BP}$ ) determined the rapid decline of natural resources in the climatically sensitive dunes and lowland environments. On the other hand along the main rivers, which were fed by large aquifers located within the massifs, seasonal water availability persisted for several millennia (Cremaschi and Zerboni 2009). Smaller rivers may have turned into ephemeral streams, or dried out rapidly, but major endorheic watercourses progressively switched into oases, seasonally reactivated by rainfall (Cremaschi et al. 2006). Coeval with North Africa, the Thar Desert (Fig. 1) desiccation began around 6 ka BP (Madella and Fuller 2006), as revealed by the Lake Lunkaransar sediment record, which after some fluctuations dried out by $5.5 \mathrm{ka}$ BP (Enzel et al. 1999). Recent paleoclimatic records from Kotla Dahar, a lake located at the north-eastern edge of the distribution of Indus settlements (Haryana, India), show a general trend towards desertification and higher evapotranspiration between 5.8 and $4.2 \mathrm{ka} \mathrm{BP}$ followed by an abrupt increase in $\delta^{18} \mathrm{O}$ values and relative abundance of carbonates, indicative of a sudden decrease in Indian summer monsoon precipitations (Dixit et al. 2014).

\section{Aridification and cultural processes}

Given the diverse physiographic characteristics of the Sahara and the Thar deserts, the climate-driven changes of the landscape likely occurred with different tempi and magnitudes, thus variably affecting past human societies. In both areas, the reconstruction of mid- to late Holocene cultural trajectories is still affected by the patchiness of radiometric data, as well as the scarcity of field-based studies that consider both morpho-sedimentary and archaeological contexts across the region. Nonetheless, during the aridification phase, archaeological evidence in these areas points to continuity of occupation, but with changes in settlement pattern, rather than fullfledged abandonment.

In the SW Fazzan, the transition from the Late Pastoral (5-3.5 ka BP) to the Final Pastoral (3.5-2.7 ka BP) marks the ultimate adaptation to hyperarid conditions and, later, the rise of the Garamantian kingdom (2.7-1.5 ka BP Mori et al. 2013). According to the most recent paleoclimatic reconstructions (Cremaschi and Zerboni 2009; see also Fig. 2), it seems that the initial phase of the Garamantian king dom was characterized by a relatively humid environment, whereas the unification of the kingdom period coincided with a clear decrease in rainfall. The end of the Garamantian kingdom occurred a few centuries after the onset of current hyperarid conditions, and was followed by a new tribal population structure and relocation in the landscape (Mori et al. 2013). Therefore, no deterministic correlation between climate or ecological changes and societal collapse can be postulated.

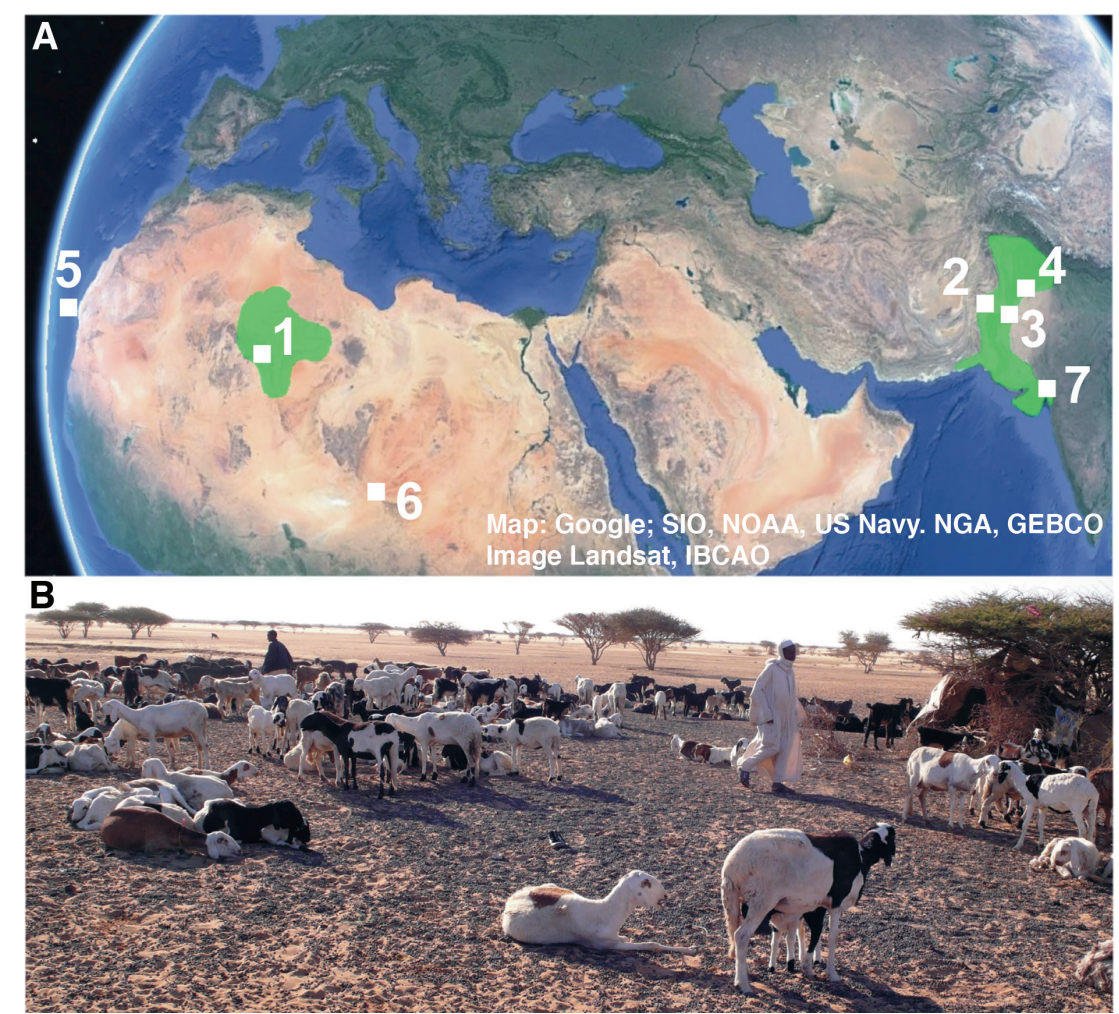

Figure 1: (A) Map with the areas (in green) mentioned in the text (central Sahara and Thar Desert; map: GoogleEarth ${ }^{\mathrm{TM}}$ ). Key: 1) Fazzan (Libya); 2) Thar Desert; 3) Lake Lunkaransar (India); 4) Kotla Dahar (India); 5) ODP Core 658C (off Mauritania); 6) Lake Yoa (Chad); 7) Lake Wadhwama (India). (B) In both regions, the study of subsistence strategies of resilient traditional societies is a tool to disclose the complexity of the responses of late Holocene archaeological communities to increased aridity. 
In north-western South Asia, the beginning of the Harappan Civilization (Early Harappan) roughly coincides with the earliest phase of aridification (5.1 $\mathrm{ka} \mathrm{BP})$, and the urbanization period (Mature Harappan) develops in spite of the drying trend. Although the end of the Harappan Civilization has often been associated with extreme climatic events, the question is still under debate. A recent study suggests a possible correlation between the 4.1 ka BP drought event and the onset of the de-urbanization period, which started a couple of hundred years later (Dixit et al 2014). However, more than a collapse, the Late Harappan period (3.8-3.2 ka BP) seems to reflect settlement reorganization in consequence to hydroclimatic changes (Giosan et al 2012), with an increased number of small and more dispersed sites that occupied diverse ecological niches. The scale of hydroclimatic stresses probably decreased the resilience of Harappan society, but on its own does not provide a straightforward, deterministic explanation for the transformations in site size, distribution, and interrelationships across the whole area.

\section{The role of an unsteady climate}

Climate change has often been invoked as a reason for cultural change, yet human dynamics are not linearly related to climate change. Humans respond to what they perceive as changes in the landscape and in the available resources. Therefore, the transition to aridity in North Africa and north-west South Asia is better interpreted as the transition to a drier, yet oscillating, climate, with marked annual (or few-year lasting) variations in rainfall, and thus in of natural resources. This might have prompted the adoption of flexible and opportunistic strategies to cope with an unpredictable alternation of wet and dry years. Garamantian and Harappan state-like entities, although born and flourished in dry spells, might not have had the level of flexibility necessary to cope with high-frequency climatic variability and its erratic resource availability. The consolidation of centrally controlled socio-economical structures, including resource redistribution networks, resulted in a loss of resilience that ultimately led to a drastic change of the social organization.

The breakdown of these state-like structures, however, did not result in the abandonment of areas, but in the beginning of new socio-economic realities. Humans embraced new settlement strategies for the exploitation of residual and spotted natural resources. Local-scale choices and the accumulated ecological knowledge played a key role in the development of adaptive modes of landscape occupation and socio-cultural practice up to the present day. The oversimplified assumption of "aridity equal to abandonment" should be carefully reconsidered. In many past and current examples, people living in areas that experience aridity trends prefer to readjust and adapt their lifestyle to new conditions rather than abandon their land. How they adapt to new environmental conditions is one of the big issues of current archaeological research in arid lands. Due to the paucity of archaeological investigations directed toward past communities in the

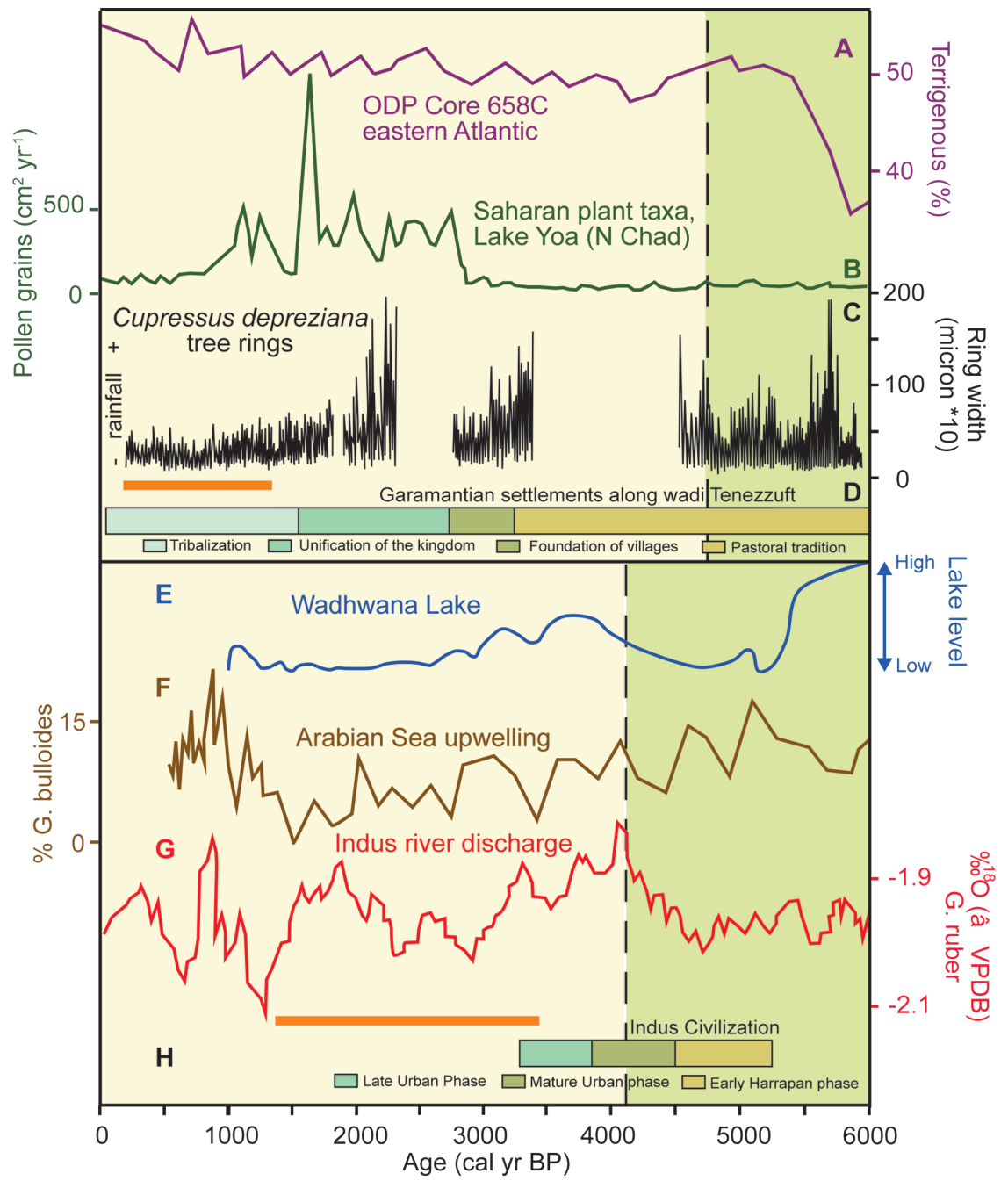

Figure 2: Correlation between climatic data and cultural evolution in the Central Sahara and the Thar Desert in the mid-late Holocene. The transition from green to yellow in the background corresponds to the transition toward aridity; the orange bars are phases of unsteady climate. (A) Termination of the African Humid Period according to terrigenous input from the Senegal River (deMenocal et al. 2000); (B) Saharan pollen record from Lake Yoa (Kröpelin et al. 2008); (C) tree rings of Cupressus dupreziana (Cremaschi et al. 2006); (D) cultural evolution of the Garamantian civilization (Mori et al. 2013); (E) Lake Wadhwana fluctuations in the Thar Desert (Raj et al. 2015); (F) record of Arabian Sea upwelling (Gupta et al. 2003); (G) changes in the Indus River discharge (Staubwasser et al. 2003); (H) cultural evolution of the Indus civilization (Dixit et al. 2014).

Sahara and the Thar deserts, much of the dynamics related to these adaptive strategies still evade our knowledge. Furthermore, in the areas discussed here, the scarcity of data for the post-Garamantian and, to a lesser extent, post-Harappan periods, prevents the construction of robust models describing demographic fluctuations during the late Holocene. Presumably (compared with present-day local adaptations), a more flexible and less-permanent settlement pattern occurred, featuring villages set around water sources (e.g. springs, oases, ephemeral streams). These villages were connected to more mobile, smaller groups adapted to exploit extremely arid areas. The (pre-)historical root of current adaptation to drylands is a key issue to refine our understanding of human dynamics in extreme environments.

\section{AFFILIATIONS}

"Dipartimento di Scienze della Terra "A. Desio", Università degli Studi di Milano, Italy ${ }^{2} \mathrm{CaSEs}$ - Complexity and Socio-Ecological Dynamics group, Barcelona, Spain

${ }^{3}$ Department of Humanities, Universitat Pompeu Fabra, Barcelona, Spain
${ }^{4}$ School of Geography, Archaeology, and Environmental Studies, University of the Witwatersrand, Johannesburg, RSA ${ }^{5}$ CREA, Barcelona, Spain

\section{CONTACT}

Andrea Zerboni: andrea.zerboni@unimi.it

\section{REFERENCES}

Cremaschi M et al. (2006) Holocene 16: 293-303

Cremaschi M, Zerboni A (2009) C R Geosci 341: 689-702 DeMenocal PB et al. (2000) Quat Sci Rev 19: 347-361 Dixit Y et al. (2014) Geology, doi: 10.1130/G35236.1 Enzel Y et al. (1999) Science 284: 125-128 Gasse F (2000) Quat Sci Rev 19: 189-211 Gupta AK et al. (2003) Nature 421: 354-357 Kröpelin S et al. (2008) Science 320: 765-768 Kuper R, Kröpelin S (2006) Science 313: 803-807 Madella M, Fuller DQ (2006) Quat Sci Rev 25: 1283-1301 Manning K, Timpson A (2014) Quat Sci Rev 101: 28-35

Mori L et al. (2013) In: Mori L (Ed) Life and Death of a Rural Village in Garamantian Times. All'Insegna del Giglio, 375-387

Raj R et al. (2015) Palaeogeogr Palaeoclimatol Palaeoecol 421: 60-74

Staubwasser M et al. (2003) Geophys Res Lett 30, doi: 10.1029/2002GL016822 